WellBeing International

WBI Studies Repository

4-2015

\title{
Microhabitat Use Affects Goby (Gobiidae) Cue Choice in Spatial Learning Task
}

G. E. White

Macquarie University

C. Brown

Macquarie University

Follow this and additional works at: https://www.wellbeingintlstudiesrepository.org/acwp_asie

Part of the Animal Studies Commons, Comparative Psychology Commons, and the Other Animal Sciences Commons

\section{Recommended Citation}

White, G. E., \& Brown, C. (2015). Microhabitat use affects goby (Gobiidae) cue choice in spatial learning task. Journal of fish biology, 86(4), 1305-1318.

This material is brought to you for free and open access by WellBeing International. It has been accepted for inclusion by an authorized administrator of the WBI Studies Repository. For more information, please contact wbisr-info@wellbeingintl.org.

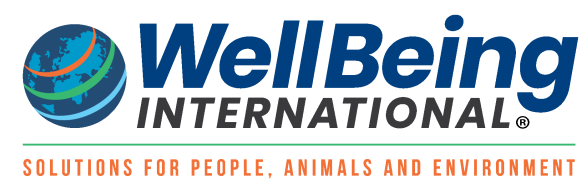




\title{
Microhabitat Use Affects Goby (Gobiidae) Cue Choice in Spatial Learning Task
}

\author{
G.E. White and C. Brown \\ Macquarie University
}

\section{KEYWORDS}

cue use, habitat stability, homing, intertidal gobies, spatial memory

\begin{abstract}
$\underline{\text { ABSTRACT }}$
This study investigated whether spatial learning ability and cue use of gobies (Gobiidae) from two contrasting habitats differed in a spatial task. Gobies were collected from the spatially complex rock pools and dynamic, homogenous sandy shores. Fishes were trained to locate a shelter under the simulated threat of predation and it was determined whether they used local or extra-maze (global) and geometric cues to do so. It was hypothesized that fishes from rock pools would outperform fishes from sandy shores in their ability to relocate shelter and the two groups would differ in their cue use. It was found that rock-pool species learnt the location of the correct shelter much faster, made fewer errors and used a combination of all available cues to locate the shelter, while sand species relied significantly more on extra-maze and geometric cues for orientation. The results reported here support the hypothesis that fishes living in complex habitats have enhanced capacity for spatial learning and are more likely to rely on local landmarks as directional cues than fishes living in mundane habitats where local cues such as visual landmarks are unreliable.
\end{abstract}

\section{INTRODUCTION}

Animals are able to orientate in familiar environments by utilizing a variety of different techniques, most of which require learning spatial information about the local environment and remembering it for future reference. These techniques can vary in complexity ranging from relatively simple, such as using beacons (a single landmark cue that signals a particular location) or chaining (following several landmarks in order), to the more complicated creation of spatial maps (where multiple cues are combined into a mental representation of the environment) (Healy, 1998; Braithwaite \& Burt de Perera, 2006; Sutherland et al., 2009). Animals may also use a body centred algorithm (series of turns) to orientate (Odling-Smee \& Braithwaite, 2003a). The techniques employed by various populations or individuals are shaped both by experience and natural selection (Odling-Smee \& Braithwaite, 2003b).

Numerous studies have explored the techniques that animals utilize to orientate in their local environments (rodents: Jeffery, 1998; birds: Kelly et al., 1998; monkeys: Gouteux et al., 2001; reptiles: Day et al., 2003); however, little is known about how these varying techniques evolved. Recent research 
has implied that an animal's habitat may influence the cues it employs to orientate (Brodbeck, 1994; Biegler \& Morris, 1996; Odling-Smee \& Braithwaite, 2003a). For example, food-storing birds utilize spatial position cues while non-storing birds prefer to use local visual landmark cues to orientate (Clayton \& Krebs, 1994). These results indicate that local visual cues may not be as reliable as spatial location cues for cache retrieval because visual cues are more likely to alter between the time of food storage and that of retrieval. The way in which an animal orientates through its environment is also constrained by the sensory system it utilizes. For example, blind Mexican cave fish Astyanax fasciatus (Cuvier 1819) cannot rely on vision to aid in orientation, instead they utilize their lateral-line organ to detect near-field wave perturbations created as the fish swims towards objects, this information is then encoded into a spatial map of the environment (Burt de Perera, 2004). Animals also show a degree of flexibility in the sensory system used, using a combination of senses to improve their accuracy or to provide redundancy if one system should fail (Braithwaite \& Burt de Perera, 2006). Studies by Bonadonna \& Bretagnolle (2002) on nine species of petrel, for example, showed that petrels could use vision to find their burrows during the day but relied on smell to find their burrows at night, sometimes in complete darkness. Collectively, these studies suggest that the cues an animal uses to navigate and orientate in its environment may be constrained by the types of cues they are able to detect and their reliability in encoding spatial information.

Fishes are subjected to a wide range of cues in their naturally diverse aquatic environments, through which they are capable of obtaining information regarding their spatial location (Odling-Smee \& Braithwaite, 2003b). Furthermore, different individuals, populations, species and developmental stages are likely to face a variety of different spatial orientation problems as habitat use and requirements change. For example, many species of fish undergo dramatic changes in habitat utilization from larval to adult forms. The salmonid Oncorhynchus mykiss (Walbaum, 1792), for example, can see UV light during their early developmental stages, but they lose this ability as they move out to sea as adults (Deutschlander et al., 2001). Thus, high variability in cue use between closely related species that occupy contrasting habitats would be expected to be seen as a result of a combination of natural selection and individual experience. Three-spined stickleback Gasterosteus aculeatus L. 1758 populations from ponds use landmark cues, while those from rivers use a body centred algorithm (a series of turns) to orientate (Odling-Smee \& Braithwaite, 2003a), suggesting that the reliability of cues is more important than their availability in determining the preferred cues to use in spatial learning. It has only recently been accepted that fishes are capable of performing complex spatial tasks and are comparable to most other vertebrates in this respect (Broglio et al., 2003; Huntingford, 2003; Braithwaite, 2006). For example, the shanny Lipophrys pholis (L. 1758) successfully located the previous position of a refuge when it had been removed, indicating that these fish are able to learn and remember cues derived from their surroundings (i.e. create a spatial map) and uses this knowledge to aid in orientation (Burt de Perera \& Guilford, 2008). Similarly, Aronson $(1951,1971)$ demonstrated the ability of the frillfin goby Bathygobius soporator (Valenciennes 1837) to use a spatial map of the local topography acquired, after swimming over the area during a simulated high tide, to jump from their home tide pool to an adjacent pool with great accuracy when threatened during simulated low tide. Only fish that had been given the opportunity to swim over the artificial rock platform at high tide were able to orientate themselves correctly when performing jumps and thus land in adjacent pools.

To date, few have conducted comparative analyses of orientation behaviour in marine fishes despite their massive diversity. Gobies offer a fantastic opportunity to conduct comparative studies; there are literally thousands of species found in almost every aquatic environment. Intertidal species are of particular interest because they can be easily collected from highly contrasting habitats. Sandy shore species live in habitats that are highly dynamic, relatively homogeneous in nature and offer few refuges. Disturbance by wave action and currents renders the limited number of local visual landmarks unreliable for use in 
orientation (Gibson, 1999). Moreover, many sand-dwelling species rely on rapid zig-zagging escape trajectories followed by burying and camouflage to escape predators in the absence of a reference. Although, sand species will utilize refuges such as rocks, logs and sea grass if available. Rock pools, on the other hand, are structurally complex and relatively stable habitats. These pools contain holes and crevices in the rock substratum, large boulders and algae, all of which provide reliable refuges at low tide (Gibson, 1982; Silberschneider \& Booth, 2001). The best escape strategy in this context would be to learn and remember the location of a place to hide and be able to enter this refuge quickly when under threat. Many rock-pool-dwelling fishes consistently return to a particular rock pool to seek refuge during low tide and thus acquire an accurate knowledge of the layout of their home pool (Gibson, 1967, 1999; White \& Brown, 2013). It is likely that the species occupying these two contrasting habitats differ in their spatial learning and memory capabilities and the cues they use for orientation.

This study determined whether gobies collected from two contrasting habitats, rocky intertidal pools and sandy shores, differed in their spatial learning and memory capabilities. It was predicted that natural selection would favour the evolution of enhanced spatial memories in rock pool-dwelling species because the location of refuges remain stable over time. Sandy shore species, by contrast, would not be susceptible to the same level of selection since the location of refuges is highly unpredictable. It was further predicted that gobies found in rock pools would use local landmark cues to a greater extent than sand-dwelling species.

\section{MATERIALS AND METHODS}

\section{STUDY ANIMALS}

Four common species of intertidal gobies collected from two contrasting habitats in the Sydney region of New South Wales, Australia, were tested for specific cue use during a spatial learning task. Two rocky intertidal species: Cocos frillgoby Bathygobius cocosensis (Bleeker 1854) and Krefft's goby Bathygobius krefftii (Steindachner 1866), collected from rock pools at low tide from a number of rock platforms, and two sand-dwelling species: eastern longfin goby Favonigobius lentiginosus (Richardson 1844) and Hoese's sandgoby Istigobius hoesei Murdy \& McEachran 1982, collected form a number of sandy beaches. These fishes were collected from healthy populations outside of the breeding season and thus removal of individuals did not affect population stability. Fishes were captured by hand-nets and transported in groups of 12 in insulated aerated tanks $(30 \mathrm{~cm} \times 25 \mathrm{~cm} \times 20 \mathrm{~cm})$ back to the laboratory. Transportation involved a brief trip ( $\leq 1 \mathrm{~h})$ in a vehicle and posed no threat to the fish's long-term wellbeing. Stress was minimized by keeping fishes in cool, dark conditions during transport and filling tanks completely with water to limit irregular water movement.

A total of 48 fish were tested for cue use (c. 12 of each species) ranging in age from sub-adults to adults (3.2-7.0 cm total length, $L_{T}$ ). Fishes were allowed to settle in the laboratory for a period of 1 month before testing began. They were housed in groups of 12 in four flow-through seawater aquaria $(64 \mathrm{~cm} \times 42 \mathrm{~cm} \times$ $26 \mathrm{~cm}$ ) held in a seawater facility. These fish are normally found living in close proximity to one another (i.e. within the same rock pool) and thus aggression and dominance displays between individuals were minimal. All aquaria were maintained at the same seawater flow rate $\left(11 \mathrm{~min}^{-1}\right)$ and temperature (18$22^{\circ} \mathrm{C}$ ), and were illuminated for $12 \mathrm{~h}$ each day with full spectrum lights. Within the aquaria, fishes were provided with a substratum composed of shell grit and places to hide (i.e. plastic plants, rocks, PVC pipes and large empty shells). Fishes were fed a combination of live brine shrimp Artemia franciscana, live black worms Lumbriculus variegates and commercial dry food (tetra colour bits) every second day during the settling period. Three weeks before the testing began, fishes were lightly anaesthetized using a solution of $50 \mathrm{mg}^{-1} \mathrm{MS}-222$ buffered with sodium bicarbonate (fishes placed in a bucket containing 1.51 solution until subdued), their $L_{T}$ was measured and they were marked using visible implant fluorescent 
elastomer tags (VIE; Northwest Marine Technology, Inc.; www.nmt.us/products/vie/vie.shtml). VIE tags were injected beneath the fishes' dorsal epithelium in a combination of six sites to aid in fish identification. This entire procedure took $c$. $2 \mathrm{~min}$ to perform on each fish. After tagging, the fishes were allowed to recover in a bucket of fresh seawater before releasing them back into their storage tanks, none of the fishes showed any side-effects caused by tagging procedures.

\section{APPARATUS}

Two rectangular arenas $(30 \mathrm{~cm} \times 50 \mathrm{~cm}$ and $15 \mathrm{~cm}$ high) constructed from $3 \mathrm{~mm}$ white opaque PVC plastic were submerged into aerated seawater to a depth of $10 \mathrm{~cm}$ within a larger rectangular pool (1.3m $\times 0.85 \mathrm{~m}$ and $0.2 \mathrm{~m}$ high) connected to a flow-through system (Fig. 1). Each arena contained a layer of shell grit covering its base and an artificial shelter (half a ceramic pot, diameter $7 \mathrm{~cm}$ ) at each end; one shelter was made accessible to the fish while the other was blocked by a piece of clear PVC plastic (Fig. 2). To locate the correct shelter, the fish had to learn to either follow local (plant landmark) or other cues such as extra-maze (global) or geometric cues created by the rectangular shape of the test arena. Black curtains surrounded the test arena to prevent disruptions created by the viewer; however, these curtains did not obstruct the fish's view of external global cues such as those above the arena (i.e. positions of lights, water inflow pipes and cameras). Fish behaviour was monitored remotely on a laptop computer connected to a web camera (Microsoft Lifecam VX-2000; www.microsoft.com) positioned 1m above the centre of each maze. Trials were recorded directly to an external hard drive connected to the laptop computer.

\section{PRE-TRAINING}

The function of pre-training was to allow fishes to become familiar with the test arena. During pre-training, no landmarks were present, but both shelters were made available (i.e. entrance was not blocked by clear PVC plastic). Groups of 12 fishes were captured and transferred to each of the two test arenas using small hand-nets. These fishes were then given free access to the entire test arenas for $24 \mathrm{~h}$ before returning to their home tanks prior to training. Both test arenas were used simultaneously.

\section{TRAINING}

At the start of a trial, a single fish was captured from its home tank using a small hand-net and placed into a clear plastic cylindrical container $(5 \mathrm{~cm}$ diameter $\times 8 \mathrm{~cm}$ high) in the middle of each of the two test arenas and given $1 \mathrm{~min}$ to settle before the container was gently raised. The water directly above the fish was squirted with a water pistol to encourage it to make a dash for the shelter. A water pistol was used to simulate an aerial predator attack, as many shore birds, including egrets, herons, cormorants and gulls, are known to prey upon rock-pool and sand-dwelling gobies (Rathbun, 1991; Stevens et al., 2014). Occasionally, the fish was startled by the raising of the container before the water pistol could be utilized, when this occurred the raising of the container was counted as the simulated predator attack. During training trials, both test arenas were used simultaneously, thus two animals were trained at the same time, one in each test arena. To control for any initial side biases, half the fish from each species were trained to seek shelter on the left and half seek shelter on the right. Records were kept of the number of escape attempts into the wrong shelter (errors), which shelter the fish chose first and latency to find the correct shelter. Shelter entry was determined to have taken place when the entire fish was under cover. To complete a trial successfully, fishes had to swim into the accessible shelter before trying to enter the inaccessible shelter. Once fishes had entered the correct shelter, they were left for a further 3 min before the trial was terminated. If the fish tried to enter the inaccessible shelter first, this trial was scored as 'incorrect'. If the fish did not enter the correct shelter after 3min, the trial was terminated. Upon 
termination, fishes were encouraged to swim into the correct shelter (i.e. if they had not entered it during the trial) using a small hand-held net and they were allowed to occupy the shelter for $3 \mathrm{~min}$.

Fig. 1. Plan view showing the relative positions of the test arenas (A1 and A2), within the large rectangular pool. The locations of the extra-maze cues are also depicted on the diagram, water inflow pipes (C) projected down from the ceiling and into the large rectangular pool to the left of one test arena (A1) and the right of the other (A2), a drain (B) was located on the lower left hand side of the large rectangular pool closest to test arena A1, located on the ceiling above the test arenas was a large UV commercial surface light and two web cameras (D), one positioned above test arena A1 and the other over A2. Black curtains surrounded the entire apparatus to prevent disruptions created by the viewer. The rectangular test arenas (A1 and A2) (_ represent the position of the test arena during pre-training, training and the first probe trial, and the rectangular test arena $\left({ }_{-}{ }_{-}\right)$represents the position of the test arena after its $90^{\circ}$ rotation for the second probe trial $\rightarrow$, the direction in which the test areas was rotated by $90^{\circ}$ for the second probe trial; $\star$ black star, the location of the plant landmarks; $\star$ grey star, the new position of the plant landmarks after the maze has been rotated $90^{\circ}$ for the second probe trial.

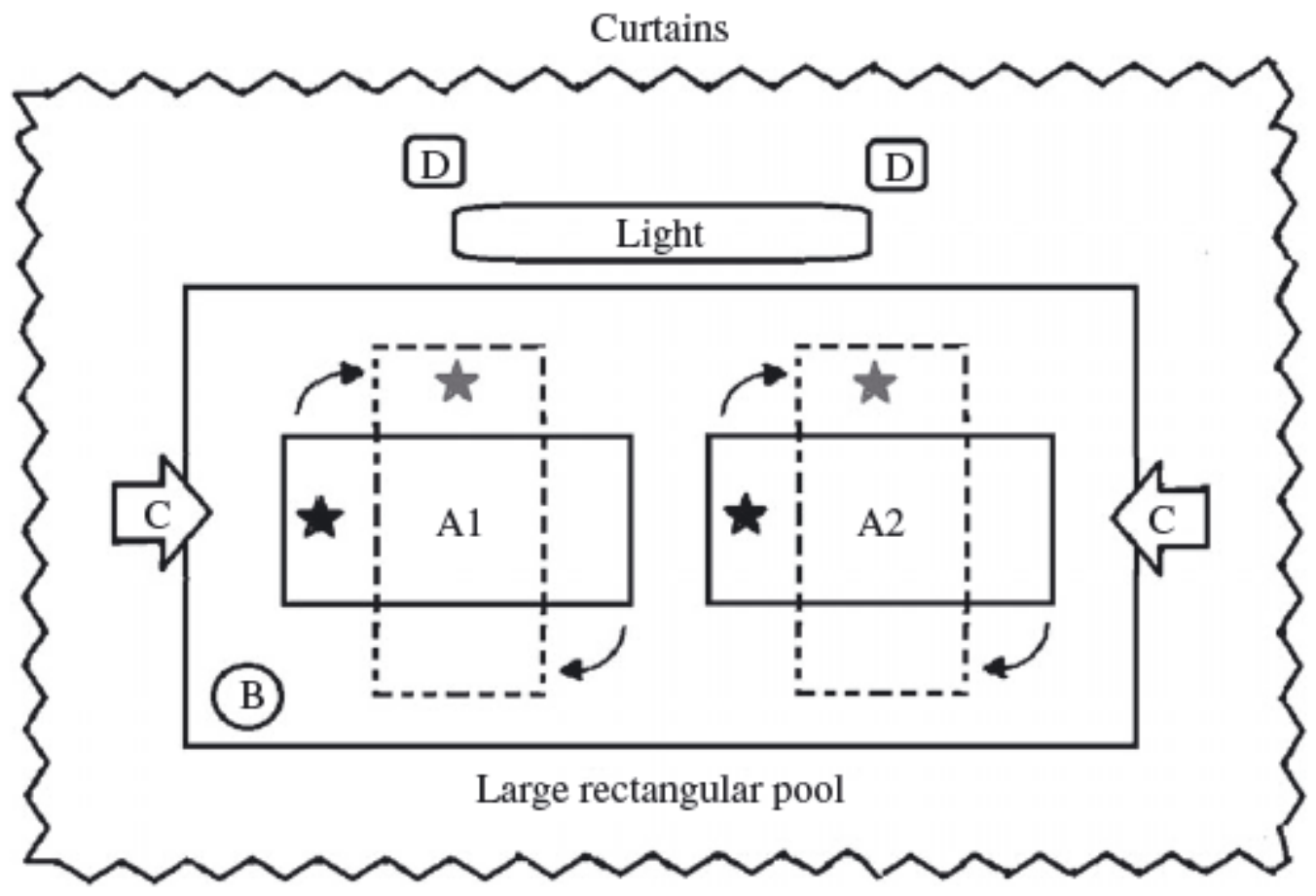

Fishes were given three trials every second day. To ensure that each individual had learned the task, fishes had to perform eight correct trials out of 10 . Fishes were trained until they had reached these criteria. Once fish reached criteria, they were given a probe trail.

\section{PROBE TRIALS TESTING FOR CUE USE}

To test whether there were different preferences for cue use between gobies collected from differing habitats, two different probe trials were performed. In the first probe trial, the internal orientation cue (plant landmark) was positioned on the opposite side of the tank from training. By observing which shelter the fish entered, it was possible to determine if the fish were using local landmarks to orientate. If fish entered the shelter with the plastic plant landmarks, a 'local cue' response was recorded. If fish entered the same shelter as it did during training, then the 'other cue' response was recorded (i.e. might be using geometric information or global cues). During the probe trial, both shelters were accessible so the fishes 
were not punished for choosing one or other of the available cues. Fishes were allowed to enter a shelter and hide there for a period of 3 min before they were removed from the test arena.

Fig. 2. Diagram of the test arena set-up for a training trial, in the centre of the arena is the clear cylindrical start container (A) housing the test fish. The locations of the incorrect shelter (B) with clear plastic partition blocking entrance and the correct shelter (C) with an open accessible entrance are shown at opposite ends of the test arena. The plastic plant landmarks (D) are positioned on either side of the entrance to the correct shelter (C).

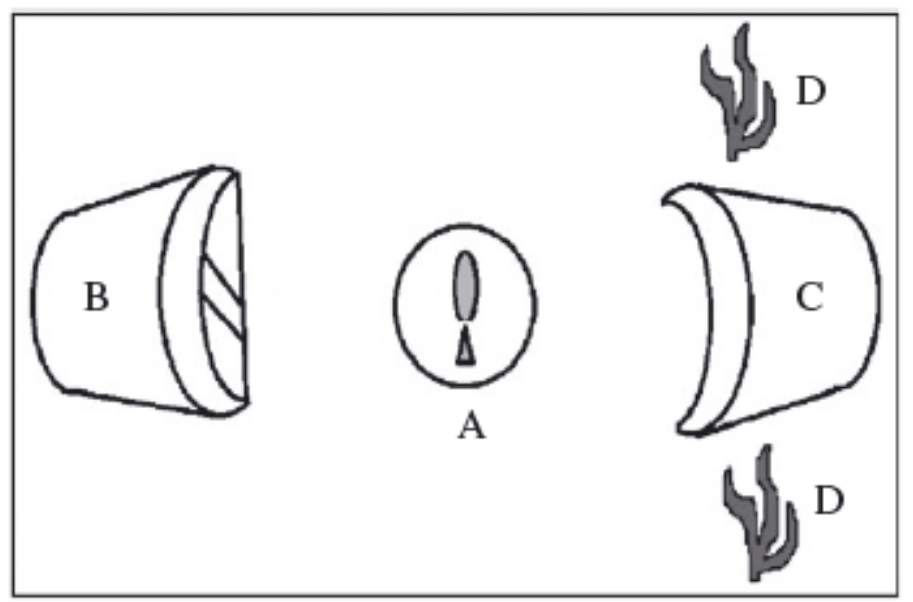

After the first probe trial, each fish was given at least 10 training trials, during which they needed to choose the correct shelter for eight of the 10 consecutive trials in order to progress to the second probe trial. The second probe trial involved rotating the test arena by $90^{\circ}$ (Fig. 1). The internal orientation cues, plant landmarks, were positioned in the same place as training trials, but extra-maze cues were located in completely different positions to training trials. For example, water inflow pipes that were originally located behind a shelter during training trials were instead located on one side of the test arena during the second probe trial, and the long commercial light located on the ceiling above the arena originally appeared in a horizontal position to the fish during training trials instead appeared in a vertical position to the fish during the second probe trial. If fishes were using local cues, or the geometry of the test arena, they would enter the shelter with the plastic plant landmarks with no hesitation. If, on the other hand, fishes were using global cues (extra-maze), then they would be totally disorientated, execute many $180^{\circ}$ turns, swim into the walls and finally enter either shelter. Once again, both shelters were made accessible to the fishes so that they were not punished for choosing either local or global cues to orient.

Two behaviours indicating 'confusion' were scored from video recordings of the second probe trial. A '180。 direction reversal' was scored if fishes swam in one direction stopped to make a $180^{\circ}$ turn and swam in the opposite direction. A 'wall collision' was scored if fishes swam into either of the arena sidewalls, which indicated they were homing to the original position of the shelters in relation to global cues. Wall collisions did not appear to cause the fishes any harm as they did not hit them with much force. Behaviours were scored immediately after the start container was raised and simulated predator attack began, scoring stopped once fishes had entered a shelter.

Testing lasted for a period of no longer than 2 months. During this 2 month period, fishes exhibited no habituation to the threat stimulus despite its repeated use. Once testing was complete, fishes were killed by over-anaesthetization in 50mg $1^{-1} \mathrm{MS}-222$ buffered with sodium bicarbonate (fishes placed in a bucket containing 11 solution for $1 \mathrm{~h}$ beyond recoverable anaesthetization to ensure death) this is a painless 
procedure and stress is limited for the fish. Specimens were then used in experiments exploring brain morphology.

\section{STATISTICAL ANALYSIS}

In most cases, data were found to be normally distributed but where necessary non-parametric statistics were used. To test if learning task performance was affected by habitat type or species differences, an analysis of variance (ANOVA) design was utilized with number of trials to first probe trial, or percentage of errors to first probe trial as the dependent variable, and habitat or species as factors. A repeated-measure ANOVA (rmANOVA) was used to compare the time fishes required to complete the spatial task during the first training trial and the last training trial (i.e. training trial before probe trial 1 began). Size was not included in any of the above comparative analyses because it is confounded by species differences in size. Instead, size was analysed at a species level for each of the four performance measures using regressions; all size interactions were found to be insignificant $(P>0.05$ in all cases).

A $x^{2}$ test was used to determine whether rock-pool species and sand species differed in the types of spatial cues used (i.e. local or global) during the probe trials. This test questioned whether the proportion of rock-pool species using landmarks was different to that of the sand-dwelling species. The $x^{2}$ test was also performed for each species separately. To test fish 'confusion' in probe trials 1 and 2, two separate rmANOVAs were used to compare the time fishes required to complete the spatial task during the last training trial and the first probe trial or second probe trial. Fish 'confusion' in probe trial 2 was further analysed by performing an ANOVA with 'reversal' or 'wall' scores as the dependent variables and habitat or species as the independent variable. Confusion data were log10 transformed before analysis to meet the required assumptions of homogeneity of variance and normality of residuals. All statistical analyses were performed using StatView Version 5.0.1 (SAS Institute Inc.; www.sas.com) and Excel version 12.2.3 (Microsoft; www.microsoft.com).

\section{RESULTS}

\section{LEARNING TASK PERFORMANCE}

As predicted, the rock-pool species required fewer trials to reach the first probe trial than sand-dwelling species (ANOVA; $F 1,44=15 \cdot 399, P<0.001$ ). Bathygobius cocosensis learnt the location of the correct shelter the fastest, followed closely by $B$. krefftii, while the two sand-dwelling species, $I$. hoesei and $F$. lentiginosus, took significantly longer to learn (ANOVA, $F_{3,40}=4.812, P<0.01$ ) (Fig. 3). Furthermore, sand species made significantly more errors before reaching the first probe trail than did rock-pool species (ANOVA, $F_{1,44}=10.474, P<0.01$ ) (Fig. 4). Favonigobius lentiginosus made the most errors followed by $I$. hoesei and $B$. krefftii, with the rock-pool species $B$. cocosensis making the least errors (ANOVA, $F_{3,40}=3.837, P<0.05$ ). There was a significant improvement in time required by all fishes regardless of species to solve the spatial task as the number of training trials increased, with fishes solving the spatial task much faster in the last training trial (i.e. before probe trial 1 began) than in the first training trial (rmANOVA, $\left.F_{1,46}=4 \cdot 075, P<0.05\right)$. Sand species also took significantly longer to solve the spatial task than did rock-pool species (rmANOVA, $F_{1,46}=5.734, P<0.05$ ). Favonigobius lentiginosus acquired the highest latency time score followed by $I$. hoesei and $B$. krefftii, with the rock-pool species $B$. cocosensis acquiring the lowest latency time score (ANOVA, $F_{3,44}=4.213, P<0.05$ ).

\section{SPATIAL CUE USE}

During the first probe trial, where the plant landmarks were shifted, rock-pool-dwelling species used a combination of cues (local and other) to orientate, whereas sand-dwelling species relied solely on other 
cues for orientation $\left(X^{2}\right.$, rock pool $P>0.05$; sand $\left.P<0.01\right)$ (Fig. 5). It was found that $B$. cocosensis and $B$. krefftii relied on both plant landmarks and other cues to orientate $\left(X^{2}\right.$, both $\left.P>0.05\right)$, while $F$. lentiginosus and $I$. hoesei relied more readily on other cues for orientation $\left(X^{2}, P<0.05\right.$ and $>0.05$, respectively). Fishes showed relatively little confusion during the first probe trial, there were no obvious differences in the time fishes required to complete the spatial task between the last training trial and probe trial 1 (rmANOVA, $F_{3,44}=0.987, P>0.05$ ). Sand species, however, took significantly longer time to solve the spatial task during probe trial 1 than did rock-pool species (rmANOVA, $F_{1,46}=11.392, P<0.01$ ). Favonigobius lentiginosus acquired the highest latency time score followed by I.hoesei and $B$. krefftii, with the rock-pool species $B$. cocosensis acquiring the lowest latency time score (ANOVA, $F_{3,44}=9 \cdot 876, P<$ $0.001)$.

Fig. 3. Mean+S.E. number of trials required by rock-pool and sand-dwelling fishes to complete the spatial learning task.

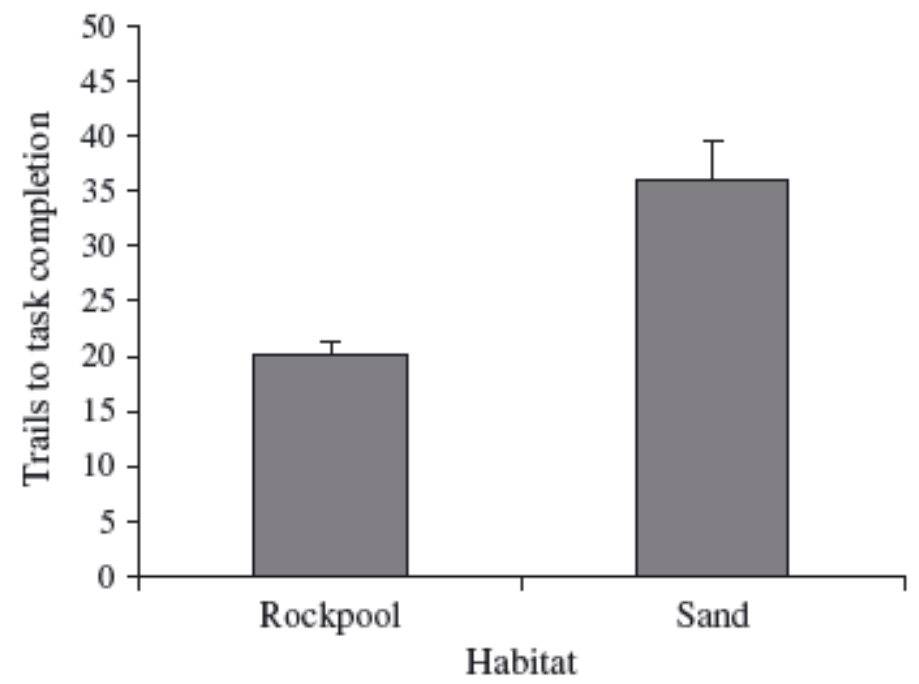

Fig. 4. The mean+S.E. percentage of errors made by rock-pool and sand-dwelling fishes before reaching probe trial stage (criteria).

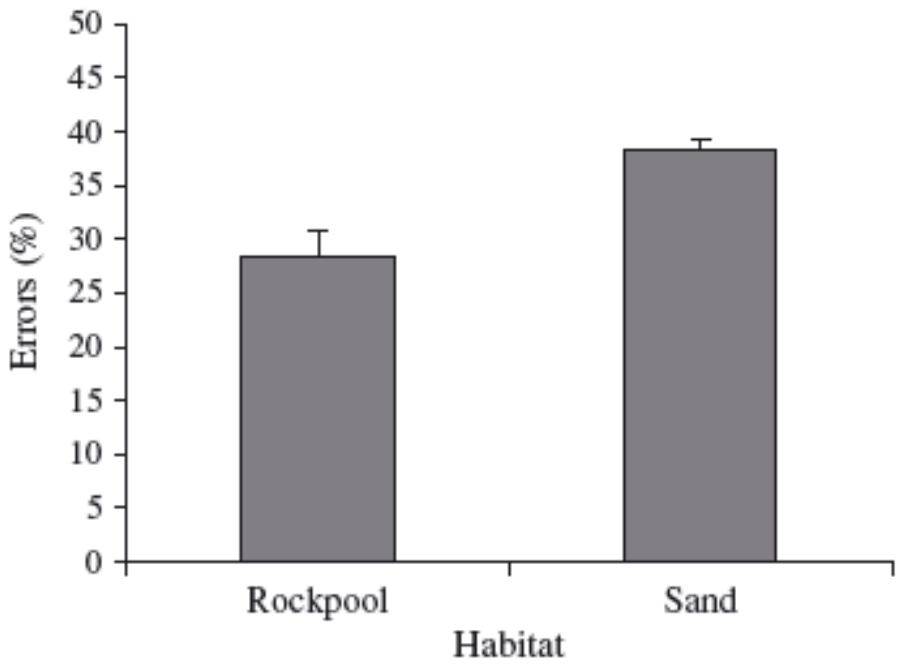


Fig. 5. Percentage of rock-pool and sand-dwelling fish using internal landmarks ( $\square$ ) and external cues $(\square)$ for orientation during probe trial 1.

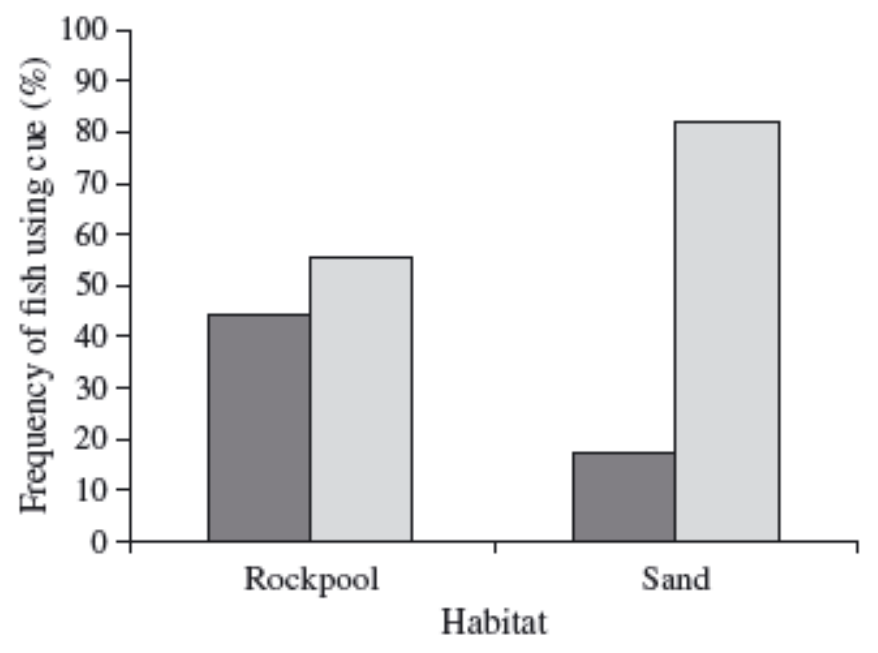

During the second probe trial, where the maze was rotated $90^{\circ}$, all species regardless of habitat used a combination of cues to orientate $\left(x^{2}, P>0.05\right.$ in all cases). On a species basis, however, the rock-pool species, $B$. krefftii, had a slight tendency to use internal landmarks for orientation; however, this was not significant $\left(X^{2}, P>0.05\right)$. Furthermore, sand species exhibited greater signs of confusion during the second probe trial than did rock-pool species as illustrated by significantly more $180^{\circ}$ reversals (ANOVA, $F_{1,46}=23.665, P<0.001$ ), swimming into the sidewalls of the arena (ANOVA, $F_{1,44}=40.017, P<0.001$ ) (Fig. 6) and longer latency scores (rmANOVA, $F_{1,46}=10.48, P<0.05$ ).

\section{DISCUSSION}

Goby species that inhabit rock pools learnt the location of the correct shelter much faster and made fewer errors during the training trials than sand-dwelling species. Rock-pool species tended to rely on a combination of cues to locate the shelter, whereas sand-dwelling species relied almost exclusively on extra-maze cues. These differences in learning ability and cue use may be the result of individual experience but most likely reflect the action of natural selection in the context of their natural habitat (ecological cognition).

\section{SPATIAL LEARNING}

The ecological cognition hypothesis suggests that the brains and behaviour of animals are shaped by their everyday experiences and the types of problems animals commonly face in their environments (Healy \& Braithwaite, 2000). Performance differences between the species in this simple avoidance task may have arisen due to natural selection acting upon genetics, differences in experience during early ontogeny, or a combination of the two. All four goby species are genetically distinct from one another; however, rock-pool species are more closely related to one another than they are to sand species and vice versa (Thacker \& Roje, 2011; White, 2014). Therefore, it is possible that an evolved difference in neural machinery and processes, arising from the different selective forces shaping the spatial learning investment for rock-pool and sandy shore habitats, is causing differences in task performance. Within spatially complex rock-pool habitats, fishes rely on remembering spatially important information such as which pools are safe to avoid being stranded in dangerous locations (White \& Brown, 2013). Even within a pool, rock-pool fishes probably recall the layout of features with high precision, including the best places 
to hide from predators (Markel, 1994; Burt de Perera \& Guilford, 2008). Sandy shores, in contrast, lack visual cues, the few that are available are highly unstable and fishes have few opportunities to seek cover when threatened thus these species utilize alternative methods of orientation.

Fig. 6. Mean+S.E. number of times rock-pool and sand-dwelling fishes executed behaviours indicating confusion during the second probe trial (arena rotation). Two measures of confusion are displayed here, $180^{\circ}$ direction reversals $(\square)$ involved fishes swimming in one direction stopping to make a $180^{\circ}$ turn and swimming in the opposite direction, and wall collisions $(\square)$ involved fishes swimming into either of the arena sidewalls.

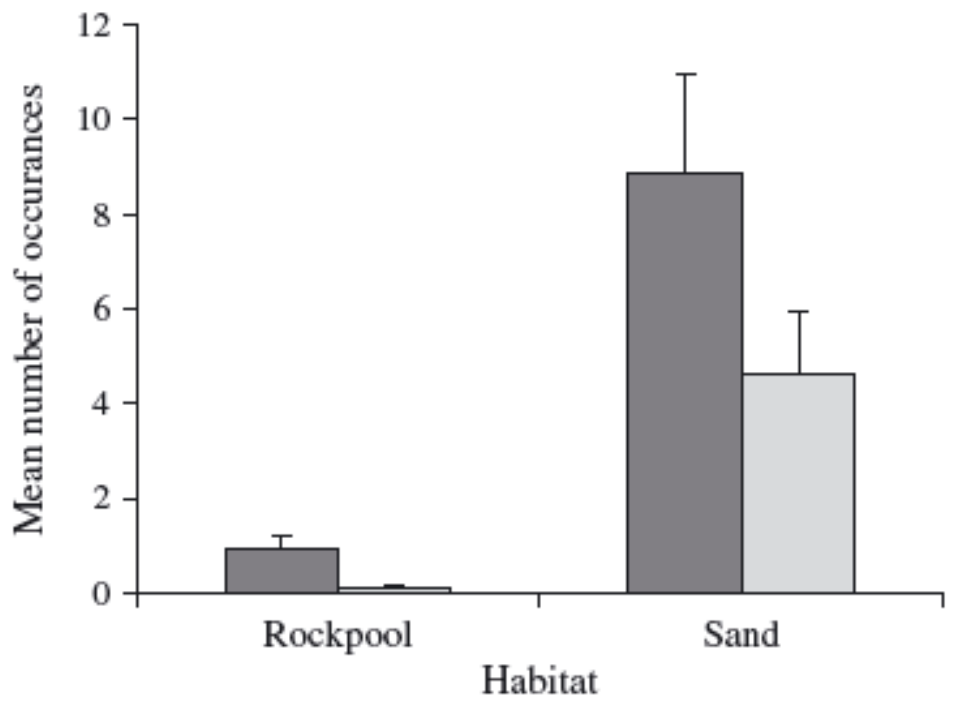

Small-bodied species such as gobies are at high risk of predation and the different predator avoidance behaviours displayed by rock-pool and sand species are likely to place differing demands on spatial learning abilities. Dodd et al. (2000) demonstrated that $L$. pholis, another small intertidal fish, were highly attracted to a dark screen when released into a novel test arena. The authors suggested that when these fish find themselves in an unfamiliar environment they swim towards the first dark area they see, as this may indicate the position of shelter such as a crevice or rocky overhang. This is likely to be true for the rock-pool gobies tested in this study. When first released into the test arena under simulated predator attack, the rock-pool fish's first response was to swim towards a shelter. In the wild, rock-pool species are only found in tide pools with refuges such as crevasses, algae cover, overhangs and rocks (Griffiths et al., 2006; White et al., in press). Shelter is relatively rare and found in unpredictable locations in sandy shore habitats, thus sand species must also employ alternative avoidance tactics such as quick zig-zag escape responses often in combination with burying under the sand when shelter is unavailable (Whitely, 1932; Murdy \& Hoese, 1985). When shelter is available, however, sand species will utilize it to avoid detection by predators. Whilst collecting sand-dwelling fishes, it was noticed that they would dart into clumps sea grass, rocks, logs or shells if available to avoid capture with hand-nets.

Another possibility is that early experience of differing spatial problems generated the differences observed in spatial learning ability between the species (Seymoure et al., 1996; Odling-Smee \& Braithwaite, 2003a). Experience of a more spatially complex environment during early ontogeny may enable individuals to learn other spatial tasks more readily later in life. For example, caching birds show limited capacity for spatial memory and reduced neural development in the absence of caching experience (Clayton, 2001). Hatchery-reared fishes exposed to enriched environmental conditions as juveniles demonstrate improved spatial learning abilities, behavioural flexibility and greater neurogenic 
expression in the forebrain (Braithwaite \& Salvanes, 2005; Salvanes et al., 2013). It may be that when fishes recruit to their respective habitats, they develop escape responses that are appropriate to that location. One could test this by rearing fishes in contrasting environments and observing the development of escape responses.

\section{CUE USE}

Studies on spatial learning in animals commonly show that navigational problems can be solved in more than one way and multiple orientation strategies are utilized at the same time providing a degree of redundancy in the orientation system (Etienne et al., 1990; Able, 1993; Collett \& Zeil, 1998; Odling-Smee et al., 2008). The present results indicate that gobies living in different habitats differ in the types of cues used to solve the spatial task. During probe trials, local cues available inside the arena were organized so they conflicted with other cues (extra-maze arena cues such as those above the arena or the geometric layout of the arena) by positioning local landmarks on the opposite side of the maze. Burt de Perera \& Guilford (2008) hypothesized that these sorts of landmarks would be similar to the types of local cues that exist within a rock pool (e.g. crevices, plants and overhangs) and extra-maze cues would be similar to those that exist outside the rock pool (e.g. view of cliffs above, position of the sun, magnetism and sound of the ocean). Obviously, geometric information could also be used to encode the location of a resource in any environment that is not symmetrical. Rock-pool fishes relied on multiple cues to locate the shelter, whereas sand species relied significantly more on extra-maze cues.

In sandy shore habitats, landmarks such as plants and rocks are rare and unstable given that they are likely to be washed away or moved by wave and tidal action. It is likely, therefore, that species living in these environments ignore such cues in favour of more reliable global cues or egocentric navigation strategies. On the other hand, rock-pool environments contain a number of relatively stable landmarks, geometric and global cues that could readily be used for orientation. Such differences in navigation strategy have also been observed between different populations of $G$. aculeatus. Fish from ponds were more likely to use landmarks for orientation than fish from rivers (Braithwaite \& Girvan, 2003; OdlingSmee \& Braithwaite, 2003a). Furthermore, Panamania bishops Brachyrhaphis episcopi (Steindachner 1878) collected from more stable rivers relied on local landmarks to navigate, while fish from less stable rivers relied on global cues (Brown \& Braithwaite, 2005).

Rotating global cues seriously challenged the fishes' spatial learning skills. Nevertheless, rock-pool species still managed to enter the shelters unhesitatingly and were more likely to follow local landmark cues to do so. Differences in swimming behaviour also suggest that sand species were more disoriented by the rotation of the experimental arena than rock-pool species as expected if they are relying on global (extra-maze) cues to locate the original location of the shelter. Sand gobies swam into the test arena sidewalls, executed more 180。 reversals and took significantly longer time to solve the task than rockpool gobies. Similar results were found by Burt de Perera \& Guilford (2008) who showed that L. pholis were able to home to the previous position of a shelter after its removal from the test tank; however, fish relied on both local and global cues to orientate.

To conclude, both the capacity for spatial learning and the cues utilized vary between species inhabiting contrasting habitats. The spatial navigation technique that a fish chooses to utilize and their learning and memory capabilities depends on the environmental challenges it faces in its local habitat as predicted by the ecological cognition hypothesis. The study shows that gobies inhabiting unstable sandy shore habitats were slower to learn the location of a hide and were more likely to use global cues to learn and remember the location than gobies found in spatially complex and stable rock-pool habitats which utilized a number of cues. Natural selection clearly favours different spatial learning approaches in different 
environments but it is possible that prior experience may also play a role. Future experiments should work towards disentangling the experiential $v$. innate spatial responses of fishes within their chosen habitats.

\section{Acknowledgements}

Many thanks are due to $P$. Brunet for assistance with laboratory testing, anonymous reviewers for comments on manuscript and Macquarie University for providing the funds necessary to perform this study. Experimental methods in this study conformed to the standards set by the Macquarie University Animal Ethics committee (ARA\# 2011/021). Fish collections were conducted under NSW Fisheries Scientific Collection Permit number P08/0010-3.0.

\section{References}

Able, K. P. (1993). Orientation cues used by migratory birds: a review of cue-conflict experiments. Trends in Ecology and Evolution 8, 367-371.

Aronson, L. R. (1951). Orientation \& jumping behaviour in the gobiid fish Bathygobius soporator. American Museum Novitates 1486, 1-22.

Aronson, L. R. (1971). Further studies of the orientation and jumping behaviour in the gobiid fish Bathygobius soporator. Annals of the New York Academy of Sciences 188, 378-407.

Biegler, R. \& Morris, R. G. M. (1996). Landmark stability: studies exploring whether the perceived stability of the environment influences spatial representation. Journal of Experimental Biology 199, 187193.

Bonadonna, F. \& Bretagnolle, V. (2002). Smelling home: a good solution for burrow-finding in nocturnal petrels? Journal of Experimental Biology 205, 2519-2523.

Braithwaite, V. A. (2006). Cognitive Ability in Fish. Fish Physiology: Behaviour and Physiology of Fish. San Diego, CA: Academic Press.

Braithwaite, V. A. \& Burt de Perera, T. (2006). Short-range orientation in fish: how fish map space. Marine and Freshwater Behaviour and Physiology 39, 37-47.

Braithwaite, V. A. \& Girvan, J. R. (2003). Use of water flow direction to provide spatial information in a small-scale orientation task. Journal of Fish Biology 63, 74-83.

Braithwaite, V. A. \& Salvanes, A. G. V. (2005). Environmental variability in the early rearing environment generates behaviourally flexible cod: implications for rehabilitating wild populations. Proceedings of the Royal Society B 272, 1107-1113.

Brodbeck, D. R. (1994). Memory for spatial and local cues: a comparison of a storing and a nonstoring species. Animal Learning and Behaviour 22, 119-133.

Broglio, C., Rodríguez, F. \& Salas, C. (2003). Spatial cognition and its neural basis in teleost fishes. Fish and Fisheries 4, 247-255.

Brown, C. \& Braithwaite, V. A. (2005). Effects of predation pressure on the cognitive ability of the poeciliid Brachyrhaphis episcopi. Behavioural Ecology 16, 482-487.

Burt de Perera, T. (2004). Spatial parameters encoded in the spatial map of the blind Mexican cave fish, Astyanax fasciatus. Animal Behaviour 68, 291-295.

Burt de Perera, T. \& Guilford, T. C. (2008). Rapid learning of shelter position in an intertidal fish, the shanny Lipophrys pholis L. Journal of Fish Biology 72, 1386-1392.

Clayton, N. S. (2001). Hippocampal growth and maintenance depend on food-caching experience in juvenile mountain chickadees (Poecile gambeli). Behavioral Neuroscience 115, 614-625.

Clayton, N. S.\& Krebs, J. R. (1994). Memory for spatial and object-specific cues in food-storing and nonstoring birds. Journal of Comparative Physiology A 174, 371-379.

Collett, T. S. \& Zeil, J. (1998). Places and landmarks: an arthropod perspective. In Spatial Representation in Animals (Healy, S., ed.), pp. 18-53. Oxford: Oxford University Press. 
Day, L. B., Ismail, N. \&Wilczynski,W. (2003). Use of position and feature cues in discrimination learning by the whiptail lizard (Cnemidophorus inornatus). Journal of Comparative Psychology 117, 440448.

Deutschlander, M. E., Greaves, D. K., Haimberger, T. \& Hawryshyn, C. W. (2001). Functionalmapping of UV photosensitivity duringmetamorphic transitions in a salmonid fish, Oncorhynchus mykiss. Journal of Experimental Biology 204, 2401-2413.

Dodd, J., Gibson, R. N. \& Hughes, R. N. (2000). Use of cues by Lipophrys pholis L. (Teleostei, Blenniidae) in learning the position of a refuge. Behavioural Processes 49, 69-75.

Etienne, A. S., Teroni, E., Hurni, C. \& Portenier, V. (1990). The effect of a single light cue on homing behaviour of the golden hamster. Animal Behaviour 39, 17-41.

Gibson, R. N. (1967). Studies on the movement of littoral fish. Journal of Animal Ecology 36, 215-234.

Gibson, R. N. (1982). Recent studies on the biology of intertidal fishes. Oceanography and Marine Biology 20, 365-414.

Gibson, R. N. (1999). Movement and homing in intertidal fishes. In Intertidal Fishes: Life in Two Worlds (Horn, M. A., Martin, K. L.M. \& Chotkowski,M. A., eds), pp. 97-125. San Diego, CA: Academic Press.

Griffiths, S. P., Davis, A. R. \& West, R. J. (2006). Role of habitat complexity in structuring temperate rockpool ichthyofaunas. Marine Ecology Progress Series 313, 227-239.

Gouteux, S., Thinus-Blanc, C. \& Vauclair, J. (2001). Rhesus monkeys use geometric and nongeometric information during a reorientation task. Journal of Experimental Psychology: General 130, 505519.

Healy, S. (1998). Spatial Representation in Animals. Oxford: Oxford University Press.

Healy, S. \& Braithwaite, V. (2000). Cognitive ecology: a field of substance? Trends in Ecology and Evolution 15, 22-26.

Huntingford, F. A. (2003). Learning in fishes. Fish and Fisheries 4, 197-198.

Jeffery, K. J. (1998). Learning of landmark stability and instability by hippocampal place cells. Neuropharmacology 37, 677-687.

Kelly, D. M., Spetch,M. L. \& Heth, C. D. (1998). Pigeons (Columba livia) encoding of geometric and featural properties of a spatial environment. Journal of Comparative Psychology 112, 259-269.

Markel, R. W. (1994). An adaptive value of spatial learning \& memory in the blackeye goby, Coryphopterus nicholie. Animal Behaviour 47, 1462-1464.

Murdy, E. O. \& Hoese, D. F. (1985). Revision of the gobiid fish genus Istigobius. Honolulu, HI: Bernice Pauahi Bishop Museum.

Odling-Smee, L.\&Braithwaite,V.A. (2003a). The influence of habitat stability on landmark use during spatial learning in the three-spined stickleback. Animal Behaviour 65, 701-707.

Odling-Smee, L. \& Braithwaite, V. A. (2003b). The role of learning in fish orientation. Fish and Fisheries 4, 235-246.

Odling-Smee, L., Boughman, J.W.\&Braithwaite, V. A. (2008). Sympatric species of three-spine stickleback differ in their performance in a spatial learning task. Behavioral Ecology and Sociobiology 62, 1935-1945.

Salvanes, A. G. V., Moberg, O., Ebbesson, L. O. E., Nilsen, T. O., Jensen, K. H. \& Braithwaite, V. A. (2013). Environmental enrichment promotes neural plasticity and cognitive ability in fish. Proceedings of the Royal Society B 280, 3113. Available at http://dx.doi.org/10.1098/rspb.2013.1331/

Seymoure, P., Dou, H. \& Juraska, J. M. (1996). Sex differences in radial maze performance: influence of rearing environment and room cues. Psychobiology 24, 33-37.

Silberschneider, V. \& Booth, D. J. (2001). Resource use by Enneapterygius rufopileus and other rockpool fishes. Environmental Biology of Fishes 61, 195-204. 
Stevens, M., Lown, A. E. \& Denton, A. M. (2014). Rockpool gobies change colour for camouflage. PLoS One 9, e110325.

Sutherland, L., Holbrook, R. I. \& Burt De Perera, T. (2009). Sensory system affects orientational strategy in a short-range spatial task in blind and eyed morphs of the fish, Astyanax fasciatus. Ethology 115, 504-510.

Thacker, C. E. \& Roje, D. M. (2011). Phylogeny of Gobiidae and identification of gobiid lineages. Systematics and Biodiversity 9, 329-347.

White, G. E. (2014). Spatial learning in intertidal gobies. PhD Thesis, Macquarie University, North Ryde, Australia.

White, G. E. \& Brown, C. (2013). Site fidelity and homing behaviour in intertidal fishes. Marine Biology $160,1365-1372$.

White,G. E., Hose G. C.\&Brown, C. (in press). Influence of rock pool characteristics on the distribution and abundance of Intertidal fishes. Marine Ecology. doi: 10.1111/maec.12232

Whitely, G. P. (1932). Fishes. Science Reports Great Barrier Reef Expedition 1928-1929 4, 267-316.

\section{Electronic Reference}

Rathbun, G. (1991). Status of declining aquatic reptiles, amphibians, and fishes in the lower Santa Rosa Creek, Cambria, California. Report to Greenspace; A Land Trust, Cambria, CA. Available at http://www.greenspacecambria.org/Documents/SR\%20Creek\%20Report\%20on\%20Reptiles,\%20 Amphibians\%20and\%20Fishes.pdf/ (last accessed 28 December 2014) 